\title{
O DISCURSO SOBRE A ABERTURA DAS UNIVERSIDADES BRASILEIRAS ÀS MIGRAÇÕES CONTEMPORÂNEAS NO JORNALISMO DIGITAL
}

\author{
The Discourse over the Opening up of \\ Brazilian Universities to Contemporary \\ Migrations in Digital Journalism \\ El Discurso sobre la apertura de las \\ universidades brasileñas para la migración \\ contemporánea en el periodismo digital \\ Marluza da Rosa* \\ Universidade Federal de Santa Maria (UFSM), \\ Departamento de Ciências da Comunicação, Frederico Westphalen, RS, Brasil
}

\begin{abstract}
Resumo: Este artigo estuda o funcionamento do discurso jornalístico sobre o acesso de estudantes refugiados(as) ao ensino superior brasileiro. O recorte temporal da pesquisa abrange os anos de 2015 a 2019, período em que o número de instituições com "acesso facilitado" aumentou significativamente, assim como sua visibilidade nas mídias. São analisadas cinco sequências discursivas extraídas de cinco notícias, selecionadas de um arquivo de vinte e três textos jornalísticos, difundidos em portais on-line no referido período. A partir do olhar teórico-metodológico dos estudos do discurso franco-brasileiros e considerando as especificidades do discurso jornalístico em meio digital, o estudo discute as práticas discursivas que inscrevem o ingresso na universidade como promessa tanto de inserção socioeconômica, quanto de integração no país de chegada.
\end{abstract}

Palavras-chave: Análise de discurso. Jornalismo digital. Universidade. Migração. Refugiado.

\begin{abstract}
This paper analyzes the functioning of the journalistic discourse on the access of refugee students in Brazilian higher education. The research comprehends the period from 2015 to 2019, where the number of institutions with "easy access" increased significantly, as well as the visibility of those subjects in the media. We based the analysis on five discursive sequences, these extracted from five news, and selected from an archive containing 23 journalistic texts published on online portals in the aforementioned period. From the theoretical and methodological perspective of Franco-Brazilian discourse studies, and considering the specificities of the journalistic discourse in digital media, the study discusses different discursive practices that inscribe the university entrance as a promise of both socioeconomic insertion and integration in the country of arrival.
\end{abstract}

Keywords: Discourse Analysis. Digital journalism. University. Migration. Refugee.

Resumen: Este artículo estudia el funcionamiento del discurso periodístico sobre el acceso de estudiantes refugiados(as) a la enseñanza superior brasileña. El recorte temporal de la investigación cubre los años de 2015 hasta 2019, curso de tiempo en lo que el número de instituciones con acceso facilitado aumentó significativamente, así como su visibilidad en las medias. Son analizadas cinco secuencias discursivas extraídas de cinco noticias, seleccionadas de un archivo de veintitrés textos periodísticos, difundidos em portadas en línea en el dicho período. Desde una mirada teórico-metodológica de estudios del discurso franco-brasileños y considerando las especificidades del discurso periodístico en medio digital, el estudio

\footnotetext{
* Doutora em Linguística Aplicada pelo Instituto de Estudos da Linguagem da Universidade Estadual de Campinas (IEL/UNICAMP). Docente da UFSM/FW. ORCID: http://orcid.org/0000-0002-3590-1752. E-mail: marluza.rosa@gmail.com.
} 
discute prácticas discursivas que inscriben la admisión en la universidad como promesa de inserción socioeconómica y de integración en el país de llegada.

Palabras clave: Análisis del discurso. Periodismo digital. Universidad. Migración. Refugiado.

Se quisermos ser donos de nosso futuro, devemos, fundamentalmente, levantar a questão do hoje. Por isso, para mim, a filosofia é uma espécie de jornalismo radical.

(Foucault, 1994) $^{1}$

\section{CONSIDERAÇÕES INICIAIS}

Neste estudo, propomos um olhar para o modo como o discurso sobre o acesso de pessoas refugiadas ao ensino superior brasileiro se produz e se difunde no âmbito midiático, notadamente no discurso jornalístico. Se, por um lado, as mídias têm dado considerável destaque às migrações, ou à chamada "crise migratória", nestes últimos anos, por outro, o processo de inclusão de migrantes no novo país tem recebido pouca ou quase nenhuma ênfase. No que concerne ao acesso e à participação no ensino superior, como afirmam Lenette, Baker e Hirsch (2019) e como o corpus deste estudo aponta, a atenção das mídias tem sido bastante limitada. Não é raro, contudo, que as populações em deslocamento sejam representadas em termos numéricos (BRÉANT, 2012) ou como força de trabalho e mão de obra, qualificada ou não (BUENO, 2017), a despeito de outros aspectos como a diversidade linguística, cultural e epistemológica.

A falta de interesse midiático pela questão migratória no que tange ao acesso a bens como a educação, por exemplo, contribui para a construção do valor social (e do valor notícia) dessa questão, frente à opinião pública, como algo menor ou secundário, o que consiste em um empecilho para que a educação seja vista como uma via possível de tomada da palavra e do espaço pelo sujeito migrante. Com vistas a compreender a (re)apresentação desse sujeito pelo texto jornalístico, analisamos a construção discursiva das notícias sobre seu (im)possível ingresso na universidade. Pensamos, assim, com Foucault (1973), no que acontece em nosso entorno, levantando a questão fundamental de refletir sobre a atualidade.

Nessa conjuntura, são diversos os dizeres em circulação sobre as pessoas em situação de refúgio, dentre os quais destacamos, como textualização do discurso institucional, o relatório Tendências Globais: Deslocamentos forçados em 2017², da Organização das Nações Unidas (ONU), segundo o qual o Brasil é o país da América Latina que recebe maior número de pedidos de refúgio. Embora essa população em

\footnotetext{
${ }^{1}$ No original : «Si nous voulons être maîtres de notre futur, nous devons poser fondamentalement la question de l'aujourd'hui. C'est pourquoi, pour moi, la philosophie est une espèce de journalisme radical ».

${ }^{2}$ Disponível em: https://www.unhcr.org/5b27be547. Acesso em: 20 fev. 2019.
} 
deslocamento seja majoritariamente jovem ${ }^{3}$, de acordo com o Alto Comissariado das Nações Unidas para Refugiados (ACNUR), apenas 3\% estão matriculados em universidades ${ }^{4}$, o que vai de encontro ao que defende a ONU quanto à necessária inclusão dos(as) migrantes nas novas realidades locais. Todavia, contraditoriamente, o número de instituições de ensino superior públicas brasileiras com programas específicos de ingresso para refugiados tem aumentado no país nos últimos anos. Desde a implementação da Cátedra Sérgio Vieira de Mello, em 2003, até 2019, foram mais de vinte as universidades públicas e privadas conveniadas, treze com ingresso facilitado regulamentado ${ }^{5}$. Destas, onze são universidades federais, gratuitas e socialmente referenciadas.

A constituição do corpus desta análise, portanto, visa a trazer para o debate o elo entre o momento histórico-social em que vivemos e o modo como os discursos se constituem e circulam. Dentre estes, atentamos para o discurso sobre a relação entre migração e ensino superior no Brasil, uma vez que, se a Universidade não permanece incólume frente às mudanças sociais, é importante que sejam questionados os sentidos já instaurados/naturalizados e aqueles em vias de instauração sobre esse âmbito. Isso porque nenhuma designação - seja universidade, seja refugiados - funciona de forma unívoca, com sentidos transparentes e imutáveis.

Apresentamos aqui resultados da análise de cinco notícias acerca da chamada abertura das universidades brasileiras aos refugiados, difundidas em cinco portais on-line do Brasil. O recorte temporal compreende os anos de 2015 a 2019, quando essa problemática passou a ganhar mais visibilidade nas mídias, relacionada ao aumento do número de instituições no país com "acesso facilitado". Este recorte se justifica pela rarefação de textos jornalísticos a esse respeito antes de 2015, ano marcado pela migração forçada em grandes proporções, que ficou conhecida como crise migratória do mediterrâneo ou crise dos refugiados, muito embora se trate de uma crise dos Estadosnações e das políticas de asilo frente a esses deslocamentos populacionais (AGIER, 2018; AKOKA, 2017). Ainda que o acesso de refugiados às universidades brasileiras exista desde o início dos anos 2000, foi a partir de 2015 que as notícias a esse respeito aumentaram consideravelmente, inserindo a problemática, ainda que de forma incipiente, na memória discursiva (PÊCHEUX, 1999; COURTINE, 2006), sempre social e coletiva, da população brasileira.

Assim, cabe destacar a importância das mídias na consolidação dessa memória, bem como a necessidade de reflexão acerca desse papel, o que justifica a problematização do discurso jornalístico aqui proposta. Para tanto, apresentaremos, primeiramente, uma breve leitura sobre o papel das mídias (em geral) e do jornalismo (em específico) na construção do presente. Em seguida, descreveremos os procedimentos de constituição do corpus de análise deste estudo para, então, encaminharmos a discussão sobre o modo

${ }^{3}$ Segundo relatório de 2018, aproximadamente 38\% dos refugiados reconhecidos pelo processo de elegibilidade no Brasil possuem entre 18 e 29 anos e aproximadamente $42 \%$ possuem entre 30 e 59 anos. Disponível em: https://www.acnur.org/portugues/wp-content/uploads/2019/07/Refugio-emnu\%CC\%81meros_versa\%CC\%83o-23-de-julho-002.pdf. Acesso em: 20 abr. 2020.

${ }^{4}$ Disponível em: https://www.acnur.org/portugues/2019/09/27/educacao-de-refugiados-5-dados-que-voceprecisa-saber/. Acesso em: 14 abr. 2020.

5 Disponível em: https://www.acnur.org/portugues/wp-content/uploads/2019/09/Relatorio-AnualCSVM_Digital.pdf. Acesso em: 14 abr. 2020. 
como os textos jornalísticos on-line apresentam a situação das pessoas refugiadas em relação ao ingresso na universidade brasileira, possibilitando tanto a estabilização, quanto a ressignificação de sentidos sobre as migrações e o ensino superior.

\section{JORNALISMO E HISTÓRIA DO PRESENTE: A QUESTÃO DAS MIGRAÇÕES}

Os estudos do discurso, notadamente a partir do viés foucaultiano, costumam ser pensados como um "diagnóstico do presente", de modo que analisar discursos consiste em desnaturalizar e desabituar nosso olhar daquilo que, de tão próximo e imediato, parece-nos estável, sem falhas. Contemporaneamente, esse presente é, em grande medida, atravessado e produzido pelas mídias, que se caracterizam como as principais responsáveis por construir uma "história do presente" (GREGOLIN, 2007), interpelando o leitor/espectador, difundindo e ressignificando imagens. Quando se toma as mídias como locus de análise, consequentemente, trata-se de questioná-las em sua evidência e suposta universalidade, bem como de problematizá-las em seu caráter histórico como produtoras de subjetividades e invisibilidades. Em outros termos, trata-se de compreender os jogos de força que atravessam o momento histórico-social em que vivemos, tornado visível e enunciável pelas mídias. Isso não implica afirmar que as mídias, de forma geral, ou o jornalismo, mais pontualmente, influenciam a sociedade, construindo ou desconstruindo seus preconceitos, mas que o fazer midiático/jornalístico não se separa dessa sociedade, do campo histórico e, consequentemente, do político.

Voltamos aqui nosso olhar ao discurso jornalístico, compreendido como espaço de produção de conhecimento e não apenas de transmissão de informações, o que, nos termos de Schwaab (2007, p. 14), define-se como "lugar de seleção e de construção desse acervo de conhecimentos e lugar de circulação de sentidos, a partir das escolhas do que é dito e do que é silenciado, de quem participa ativamente na definição deste conhecimento e de quem não está presente". Ainda sobre o funcionamento do discurso jornalístico, Zanella (2015, p. 30) acrescenta que, nesse discurso, "há um agenciamento do que pode e deve ser notícia, que ocorre porque há um atravessamento ideológico que delineia a linha editorial do grupo midiático, há formações discursivas nas quais ele se inscreve, há a posição de sujeito que os jornalistas assumem".

Com base na leitura dos autores, é possível afirmar que o discurso jornalístico se consolida enquanto prática sócio-histórica e política que condiciona dizeres e sentidos, marcando o modo como estes circulam e se inscrevem na história. Cabe lembrar que esse discurso, como qualquer outro, é constituído pela memória discursiva, enquanto possibilidade de repetição e regularização, que permite remontar aos pré-construídos e jáditos (PÊCHEUX, 1999), bem como pela heterogeneidade constitutiva (AUTHIERREVUZ, 1990), de modo que não se pode conceber seus efeitos de sentido senão em relação às diversas vozes que falam em seu dizer. Nos termos de Pêcheux (2016, p. 23 24), trata-se de uma "heterogeneidade irredutível: um remoer de falas ouvidas, relatadas ou transcritas, uma profusão de escritos mencionando falas e outros escritos". Logo, analisar o discurso jornalístico implica levar em consideração, além da heterogeneidade e da filiação a uma memória, as condições em que essas falas e escritos são retomados e ressignificados, ou seja, suas condições de produção, enquanto "conjuntura histórica determinada" (COURTINE; MARANDIN, 2016, p. 38). 
Considerar essa conjuntura demanda compreender também que o discurso jornalístico funciona no contexto contemporâneo, predominantemente, em meio digital. Assim, para Zanella (2015), esse domínio ressignifica e atualiza a "dimensão institucional" do jornalismo, uma vez que intervém no âmbito espacial e temporal dessa prática, produzindo efeitos de sentido diferentes. A esse respeito, deve-se levar em conta, ainda, o funcionamento das formações algorítmicas, enquanto "resultado da relação de sentidos entre o sujeito [leitor/espectador] e a máquina algorítmica" (FERRAGUT, 2019, p. 117, inserção nossa), uma vez que o acesso aos textos não se dá alheio às formações discursivas que atravessam e constituem sujeitos e discursos. Assim, em nossa leitura, uma das principais especificidades do jornalismo no digital concerne não só a sua abrangência, mas também ao modo de acesso do público leitor, ou seja, a forma de circulação desse discurso, dadas suas possibilidades de armazenamento, compartilhamento, retomada e ressignificação. Com base nos termos de Le Goff (1996, p. 542), podemos dizer que mudam os modos como esses textos, como documentos, são manejados e constituem bancos de dados, demandando uma crítica constante sobre seu papel na constituição da memória coletiva.

Consideradas as devidas distinções entre os domínios impresso e digital, atentar para o discurso jornalístico implica compreender que esse âmbito, sendo discursivo, envolve disputas de sentido, que são da ordem do político, lido aqui a partir dos estudos de Foucault (2009), Canut (2016) e Canut e Guellouz (2018). Ainda em sua Arqueologia, Foucault aponta para a "dimensão política" de uma teoria das práticas discursivas, o que permite compreender, dentre outros aspectos, que o discurso funciona enquanto prática que não só intervém, mas também produz uma realidade na qual determinados enunciados emergem, mas não outros nem todos. À luz do pensamento do autor, a compreensão de Canut (2016) e Canut e Guellouz (2018) acerca da dimensão política presente nas formas de nomear/enunciar, pode ser lida como se referindo ao fato de que tais formas tanto contribuem e se inserem na construção de uma dada realidade social, quanto resultam de um dispositivo jurídico do Estado.

A respeito do primeiro ponto, Canut $(2016$, n. p) salienta que "nomear é sempre fazer existir", o que implica a inexistência do que quer que seja fora da linguagem ou fora de práticas discursivas, em termos foucaultianos. Logo, não se trata de se perguntar o que determinado enunciado (termo, expressão, imagem), como "refugiado", por exemplo, significa ou por que acabou por preponderar, em detrimento de outros, principalmente nos cenários institucional e midiático, mas de investigar e compreender em que práticas discursivas se inscrevem os sujeitos quando empregam ou discutem tais modos de nomear/enunciar e construir dada realidade como verdadeira. Dito de outro modo, dada a "natureza eminentemente construída"7 (AKOKA, 2011, p. 13) de categorias como refugiado, migrante ou, mesmo, estudante, sob a égide de quais saberes-poderes, diríamos com Foucault (2009), é possível enunciar de dada forma e colocar em destaque determinados dizeres? Entramos, nesse primeiro ponto, na questão do político como atrelada à materialidade da linguagem, enquanto inseparável das condições sóciohistóricas de emergência dos enunciados.

\footnotetext{
${ }^{6}$ No original: "nommer c'est toujours faire exister".

${ }^{7}$ No original: "nature éminemment construite de la qualité de réfugié"
} 
Ainda na leitura de Canut (2016) e Canut e Guellouz (2018), um segundo ponto concerne à dimensão política que se impõe, ao tratarmos das questões migratórias na formulação e na circulação do discurso midiático, ao advir "de uma construção política dos Estados-nações"8. Abordamos, aqui, as políticas migratórias aprovadas pelos diferentes países - a exemplo da conferência intergovernamental para o pacto global pela segurança e regulamentação da migração, da ONU, ocorrida em Marrakech entre os dias 10 e 11 de dezembro de 2018 -, e colocadas em ação não a partir das práticas linguageiras, que tendem frequentemente à pluralidade de formas e, consequentemente, de sentidos, mas institucionais/institucionalizadas, caracterizadas notadamente por categorizações (AKIN, 1999; ANGERMULLER, 2017; NOSSIK, 2018; ROBLAIN, 2018; AKOKA, 2018), que produzem, por sua vez, uma cristalização das dimensões do político em constante transformação. Essa segunda dimensão política caracteriza também o discurso institucional que regulamenta o ingresso de pessoas refugiadas nas universidades, uma vez que é se inserindo em categorizações jurídico-administrativas, enquanto "refugiado", que muitas pessoas têm podido ingressar no ensino superior.

Esse regime discursivo no qual se inserem essas categorizações produz um processo de homogeneização (CANUT, 2016), que tende a ser difundido e solidificado pelas mídias. Assim, no que concerne ao cenário brasileiro, sob a designação político-jurídica "refugiado" são, ao mesmo tempo, reconhecidos e segregados estrangeiros de diversos locais, com suas singularidades que constituem a diversidade e a complexidade da existência humana.

Sabemos, a partir da leitura de Canut (2016), que é impossível abarcarmos com um nome seja um fenômeno social e histórico, seja um processo de constituição subjetiva. Do mesmo modo, é impossível sermos fiéis a uma realidade que se apresentaria como "objetiva" e que permaneceria imutável, apesar das disputas de sentido, dos jogos de verdade de uma época. Por essa razão, é necessário procedermos a uma análise histórica e historicizada dos dizeres, compreendendo os documentos - aí inscritos os textos jornalísticos - como monumentos, ou seja, produtos de dados tempo, espaço e sociedade, "segundo as relações de forças que aí [detêm] o poder" (LE GOFF, 1996, p. 545, acréscimo nosso). É dessa forma que atentamos para o corpus deste estudo, sendo inevitável que, nesse processo, perguntemo-nos: a partir de quais relações de poder, de quais pré-construídos já socialmente difundidos, de que memória discursiva, noticia-se a (im)possibilidade do ingresso de refugiados no ensino superior brasileiro?

\section{SOBRE A CONSTITUIÇÃO DO CORPUS}

Às condições de produção dos documentos em análise atrelam-se as relações de poder (FOUCAULT, 2009). São esses jogos de poder/verdade que produzem e referendam saberes e dizeres, definindo o que se caracteriza como uma "ordem do discurso" (FOUCAULT, 2001), na qual se estabelecem relações entre o visível/enunciável e o invisível/que se pode ou não dizer. É preciso, pois, acrescentar que, nesse conjunto, intervém o elemento linguístico, não como registro oral ou escrito

\footnotetext{
${ }^{8}$ No original: «d'une construction politique des États-nations ».
} 
descarnado, mas como campo da linguagem, campo simbólico, ou seja, sistema de representações compartilhadas. Tal dimensão simbólica permite compreender as práticas linguísticas/linguageiras como decorrentes de um trabalho social e político, "espaço de condição de possibilidade do sujeito em relação à língua" (RASIA, 2018, p. 174).

No que tange às práticas migratórias, para além do aspecto linguístico/linguageiro, "a aceleração das migrações internacionais revela as dinâmicas de mudança social, política e econômica em curso nas sociedades contemporâneas, cada vez mais complexas, plurais e diversificadas"9 (ROULLEAU-BERGER, 2010, p. 8). Essas transformações permitem-nos tomar os movimentos migratórios como determinantes para se pensar e fazer uma história do presente, um diagnóstico do presente, em termos foucaultianos, que nos forneça, ao menos, indícios para a compreensão de como se instauram e funcionam (ou não) as práticas de acolhida, difundidas principalmente pelas mídias.

Ora, não conhecemos esses movimentos como coisa em si, mas via discurso e, notadamente, via discurso sobre, principal marca do campo jornalístico. Na chamada era da convergência, são as mídias que, em grande parte, produzem e transmitem saberes e verdades, fazem circular discursos, constroem continuamente áreas de visibilidade e enunciabilidade. São elas também (embora frequentemente questionadas) lugares autorizados de discursivização, espaços em que se pode dizer, instaurar determinados sentidos, desestabilizar outros.

Por essa razão, partimos de uma pesquisa bibliográfica que envolve os estudos discursivos e procura compreender o funcionamento (político) do discurso jornalístico, quando associado às questões migratórias. Tal gesto teórico torna possível uma análise do corpus, recortado a partir de um arquivo de 23 documentos, veiculados on-line em 5 diferentes portais de notícias, acerca da problemática do ingresso de refugiados nas universidades brasileiras. A constituição do corpus não obedece a uma ordem rígida de seleção/exclusão de textos, uma vez que a análise da materialidade discursiva é realizada de modo a considerar que a construção de um arquivo "permite uma leitura que revela dispositivos, configurações significantes", ou seja, por meio do funcionamento metodológico da noção de arquivo exploram-se "os regimes múltiplos de produção, circulação e leitura de textos" (GUILHAUMOU; MALDIDIER; ROBIN, 2016, p. 116).

Para fins de constituição do corpus, foi utilizada a ferramenta de busca Google Notícias, por meio da localização das palavras-chave "universidade", "ensino superior", "ingresso", "acesso" e "refugiado(s)". Foi ainda realizada uma delimitação por língua (portuguesa), país (Brasil) e site/domínio (portais de notícias exclusivamente jornalísticos). Assim, não foram considerados para a análise os textos sobre os programas de acesso que figuram nos sites das próprias instituições de ensino ou da Organização das Nações Unidas, por exemplo.

Dada a rarefação de textos jornalísticos sobre o tema antes da crise de acolhida vivenciada por diversos países, dentre eles o Brasil, em 2015, o recorte temporal da pesquisa incidiu entre 2015 e 2019. Foi nesse período que a maior parte dos programas de ingresso para refugiados nas universidades brasileiras foi criada e/ou regulamentada.

\footnotetext{
${ }^{9}$ No original: «L'accélération de migrations internationalles révèle les dinamiques de changement social, politique et économique à l'oeuvre dans les societés contemporaines toujours plus complexes, plurielles et diversifiées ».
} 


\begin{tabular}{|c|c|c|c|c|}
\hline Anos & Textos & Títulos & Datas & Portais \\
\hline 2015 & 3 & $\begin{array}{l}\text { Refugiados universitários poderão estudar na Universidade } \\
\text { Federal do Paraná em } 2016 \\
\text { Refugiados da Síria e África reconstroem suas vidas em } \\
\text { Niterói } \\
\text { Refugiados enfrentam demora e custo elevado para revalidar } \\
\text { diploma }\end{array}$ & $\begin{array}{l}29 / 10 \\
31 / 10 \\
07 / 11\end{array}$ & $\begin{array}{l}\text { BlastingNews } \\
\text { O Globo } \\
\text { Rede Brasil Atual }\end{array}$ \\
\hline 2016 & 3 & $\begin{array}{l}\text { UEG abre inscrições para cursos gratuitos de língua } \\
\text { portuguesa a estrangeiros } \\
\text { UEG oferece vestibular especial para estrangeiros } \\
\text { refugiados em Goiás } \\
\text { ENEM 2016: Filha de refugiados tenta vaga no ensino } \\
\text { superior }\end{array}$ & $\begin{array}{l}03 / 07 \\
20 / 10 \\
06 / 11\end{array}$ & $\begin{array}{l}\text { Diário de Goiás } \\
\text { G1 } \\
\text { O Globo }\end{array}$ \\
\hline 2017 & 2 & $\begin{array}{l}\text { Cresce } n^{\circ} \text { de universidades brasileiras que acolhem } \\
\text { refugiados } \\
\text { Universidades brasileiras matricularam cerca de } 70 \\
\text { refugiados em menos de um ano, diz Acnur }\end{array}$ & $\begin{array}{l}11 / 09 \\
21 / 09\end{array}$ & $\begin{array}{l}\text { O Estadão } \\
\text { G1 }\end{array}$ \\
\hline 2018 & 5 & $\begin{array}{l}\text { Refugiados ganham bolsas para cursar universidade no } \\
\text { Brasil } \\
\text { Venezuelanos vão poder ingressar em cursos de graduação } \\
\text { da UFRR para ocupar vagas ociosas sem prestar vestibular } \\
\text { Só } 2 \text { de cada } 10 \text { vagas para refugiados em universidades no } \\
\text { Brasil são preenchidas } \\
\text { Burocracia, custos e lentidão nos processos dificultam a } \\
\text { revalidação de diplomas de refugiados } \\
\text { Ufba aprova cotas na graduação para trans e refugiados }\end{array}$ & $\begin{array}{l}10 / 03 \\
09 / 07 \\
14 / 09 \\
30 / 11 \\
22 / 12 \\
\end{array}$ & $\begin{array}{l}\text { Agência Brasil } \\
\text { G1 } \\
\text { Folha } \\
\text { G1 } \\
\text { Correio }\end{array}$ \\
\hline 2019 & 10 & $\begin{array}{l}\text { Unila abre vagas de graduação para refugiados e portadores } \\
\text { de visto humanitário } \\
\text { Processos de seleção internacional da Unila recebem quase } \\
2 \text { mil inscrições } \\
\text { Seletivo oferta } 100 \text { vagas para imigrantes e refugiados } \\
\text { UFPA aprova edital para refugiados, asilados, apátridas, } \\
\text { vítimas de tráfico e pessoas com visto humanitário } \\
\text { UEPB vai abrir vagas em cursos de graduação para } \\
\text { refugiados } \\
\text { Justiça determina suspensão de processo seletivo para } \\
\text { refugiados e imigrantes na UFRR } \\
\text { UFMS abre edital para transferências, refugiados e } \\
\text { portadores de diploma } \\
\text { Unifesp oferta vagas a refugiados e portadores de visto } \\
\text { humanitário } \\
\text { Ufrgs publica edital para ingresso de refugiados em cursos } \\
\text { de graduação } \\
\text { UFRGS oferece } 60 \text { vagas em } 33 \text { cursos a refugiados no RS }\end{array}$ & $\begin{array}{l}03 / 07 \\
08 / 08 \\
06 / 10 \\
23 / 10 \\
28 / 11 \\
30 / 11 \\
16 / 12 \\
25 / 12 \\
26 / 12 \\
26 / 12\end{array}$ & $\begin{array}{l}\text { G1 } \\
\text { Portal Foz } \\
\text { Folha de Boa Vista } \\
\text { G1 } \\
\text { Portal Correio - } \\
\text { Paraíba } \\
\text { G1 } \\
\text { Midiamax } \\
\text { Agência Brasil } \\
\text { Jornal do Comércio } \\
\text { - RS } \\
\text { G1 }\end{array}$ \\
\hline
\end{tabular}
a 2019

Fonte: Autoria própria. 
A Tabela 1, a seguir, ilustra os textos jornalísticos identificados a partir dos critérios referidos, considerando-se que, neste recorte, incidem o funcionamento dos algoritmos, enquanto maquinaria de seleção e disponibilização de conteúdo, assim como das formações algorítmicas (FERRAGUT, 2019), enquanto atravessamento dessa maquinaria pelo pesquisador que busca por determinadas palavras-chave e não outras, a partir de sua filiação, enquanto sujeito, a dadas formações discursivas e em condições históricas específicas.

Ainda no que diz respeito à constituição do corpus, consideramos que o discurso jornalístico no âmbito digital intervém nos gestos de leitura a ele direcionados. Além disso, para compreender a heterogeneidade constitutiva dos enunciados, levamos em consideração o fato de que o movimento de análise já é, por si só, uma escolha teórica, na qual o pesquisador está inevitavelmente implicado. Consequentemente, acentuamos que o papel do pesquisador na seleção e no recorte dos enunciados já é o de quem os interpreta, não só porque "a escolha de uma teoria [...] participa de um modo de leitura e interpretação"10 (SÉRIOT, 1986, p. 16), mas também porque o analista do discurso não pode "ver de fora aquilo no interior do qual o olhar é tomado" (PÊCHEUX, 2016, p. 24). Assim, abordamos o corpus não como conjunto de frases ou textos, mas como sistema de enunciados que remetem a diferentes formações discursivas, sendo os discursos compreendidos como práticas sociais (FOUCAULT, 2009), condicionadas por aspectos sócio-históricos e pela alteridade, que aí atua como heterogeneidade constitutiva.

\section{INGRESSO DE PESSOAS REFUGIADAS NAS UNIVERSIDADES BRASILEIRAS NO DISCURSO JORNALÍSTICO}

Este percurso de análise se organiza de modo cronológico, de 2015 a 2019, explorando-se, assim, uma notícia por ano. Em razão da extensão dos textos e do procedimento de segmentação do corpus, estabelecido a partir de sequências discursivas (SD), o olhar para o conjunto das notícias é inevitavelmente parcial e fragmentário, o que não impede a reflexão sobre o funcionamento do discurso e seus efeitos de sentido. Retomamos, então, para guiar a leitura das SD, as questões já expostas anteriormente: sob a égide de quais saberes-poderes é possível enunciar de dada forma e colocar em destaque determinados dizeres? Em que práticas discursivas se inscrevem os diferentes modos de enunciar?

Nas notícias aqui em discussão, a designação "refugiados" é reiterada e tomada em seu efeito de transparência, principalmente nos títulos, vindo a construir também sintagmas como "filha de refugiados" e "família de refugiados". Parte-se do efeito ideológico de evidência de que "todos sabem" o que significa ser refugiado, categoria jurídica que, no entanto, não é nada transparente. Para Calabrese (2015), discursos como os "de informação" têm se servido de categorias preestabelecidas como essa para nomear sujeitos e acontecimentos. Contudo, essas categorias, mais pontualmente a de "refugiado", segundo Stevenson e Baker (2018), podem tender ao reducionismo, por

${ }^{10}$ No original: « le choix d'une théorie [...] participe du choix d'un mode de lecture et d' interprétation ». 
reproduzirem um olhar que incide, muitas vezes, apenas sobre as desvantagens vivenciadas pelos sujeitos designados. Essa generalização do termo jurídico, assim, homogeneíza as especificidades dos movimentos migratórios e, amplamente difundida pelas mídias, tende à estabilização dos sentidos.

Nas notícias difundidas em 2015 e 2016, é dada ênfase às dificuldades e percalços dos refugiados na busca tanto pelo acesso à universidade, quanto pelo reconhecimento da formação já realizada em seus países de origem, como a seguir:

\begin{abstract}
SD1) Manchete: Refugiados enfrentam demora e custo elevado para revalidar diploma
Linha de apoio: Trâmites podem custar até R \$ 20 mil [sic] e demorar pelo menos nove meses, segundo Centro de Pesquisas América do Sul-Países Árabes. "Assim, eles ficam com os cargos de menor remuneração", diz diretor da entidade.

Excerto da notícia: "Não tem como ter uma vida normal se o estudo fazia parte do cotidiano dessas pessoas e ele deixou de existir. O exercício intelectual é fundamental para reflexão crítica, para o entendimento da própria identidade e para satisfação pessoal. Isso tem efeitos psicológicos e econômicos: como um refugiado vai se inserir no mercado de trabalho se a formação dele não é reconhecida?", questionou (Rede Brasil Atual, 7 nov. 2015) ${ }^{11}$.
\end{abstract}

A manchete apresentada na SD1 se estrutura linguisticamente na voz ativa, o que atende ao esperado dos títulos nos moldes técnicos do discurso jornalístico: clareza, concisão, linguagem direta. Todavia, também na própria estrutura podem ser pontuados traços do agenciamento desse dizer (ZANELLA, 2015), dado o emprego do verbo "enfrentar" e dos substantivos "demora", "custo [elevado]" e "diploma", este que remonta a um pré-construído no qual o diploma (produto/documento) equivale tanto à formação superior (processo), quanto à possibilidade de exercício intelectual e de reflexão crítica.

$\mathrm{O}$ verbo enfrentar, em seu emprego figurado ou não, pressupõe a existência de um outro a quem se enfrenta, com quem se disputa, a quem se combate ou supera. Na SD em análise, os trâmites para a validação do diploma universitário, mais precisamente o tempo necessário para o procedimento burocrático e seu valor monetário são apresentados como o limite ou a adversidade que pessoas refugiadas devem transpor. Esse aspecto é retomado em outra notícia (apresentada na Tabela 1, em 2018, "Burocracia, custos e lentidão nos processos dificultam a revalidação de diplomas de refugiados"), o que se atrela à memória discursiva sobre as migrações, visto que, conforme apontam Stevenson e Baker (2018), a língua estrangeira e o reconhecimento da formação educacional estão entre as principais barreiras enfrentadas por migrantes em seu país de "acolhida".

Na manchete da SD1, salientamos ainda que o sintagma "custo elevado" produz um efeito polissêmico, podendo se referir tanto ao valor financeiro quanto à dificuldade e ao esforço empreendido pelos refugiados. Esses efeitos de sentido decorrem da possível inscrição do dizer em diferentes formações discursivas, uma que se atrela ao discurso capitalista e outra que se relaciona ao que se pode chamar de discurso humanitário, apontando para a difícil realidade da migração. A partir desses efeitos e dado o atravessamento de questões de ordem econômica e jurídica, é possível apontar que a

11 Disponível em: https://www.redebrasilatual.com.br/cidadania/2015/11/refugiados-encontramdificuldades-para-revalidar-diplomas-e-ingressar-em-universidades-9509/. Acesso em: 31 jul. 2019. 
revalidação do diploma possui funcionamento simbólico, uma vez que revalidá-lo é reconhecer ao refugiado sua formação, sua profissão, de modo a garantir-lhe um lugar no novo país. Esse peso simbólico do diploma e, consequentemente, da formação superior pode ser identificado nas palavras citadas na linha de apoio - "Assim, eles ficam com os cargos de menor remuneração" - em que o pronome "eles", índice de afastamento do enunciador e marca do discurso sobre, retoma a categoria generalizante, "refugiados".

Essa afirmação pode ser tomada como transparente e opaca (PÊCHEUX, 1990), pois se pauta na evidência, social e historicamente solidificada, de que a formação universitária está diretamente relacionada a cargos com maior remuneração. Desse modo, a questão do acesso à universidade se inscreve na esfera das relações econômicas/trabalhistas, e a validação do diploma é colocada em relação de equivalência ao reconhecimento do refugiado como mão de obra qualificada (BUENO, 2017) para cargos com boa remuneração. Apenas se reconhecidamente apto e qualificado um refugiado poderia se inserir no mercado de trabalho no país de chegada, é o que pressupõe a pergunta ao final da SD1, que constrói um (e se constrói a partir de um) lugar consensual de dizer sobre o estrangeiro.

O excerto da notícia, também marcado pela heterogeneidade discursiva expressa na fala do entrevistado, reforça essa leitura, pois, embora o estudo, a reflexão crítica e o exercício intelectual sejam apresentados como necessários a uma "vida normal", a preocupação com a inserção no mercado de trabalho via reconhecimento da formação universitária - o "efeito econômico", portanto - é o que ganha destaque, na forma de pergunta ao final da SD1. Tal modo de enunciar permite compreender a construção da universidade como espaço que possibilita à pessoa refugiada, por meio do amparo econômico, inclusão como ser social, o que pode implicar que, uma vez não existindo essa inserção nas relações trabalhistas, pode não ocorrer sua valorização como sujeito com aspirações e desejos, sujeito a quem se reconhece a possibilidade de reflexão crítica e exercício intelectual.

Embora publicadas em portais diferentes, tanto a SD1, de 2015, quanto a SD2, de 2016, a seguir, enfatizam as dificuldades e expectativas dos refugiados. Em outros termos, mesmo que os portais não compartilhem da mesma linha editorial, essa parece ser a única forma a partir da qual se enuncia a relação entre migração e ensino superior. Cabe ao refugiado buscar um (novo) caminho em direção ao sonho prometido, como pode ser observado na SD2; sonho e dificuldade, em uma divisão política de sentidos vivenciada pelas pessoas migrantes, para quem o ensino superior se apresenta como promessa: almejada, mas adiada.

SD2) Manchete: ENEM 2016: Filha de refugiados tenta vaga no ensino superior

Linha de apoio: Pai de Hannah Matoko é iraniano e veio para o Brasil depois de fugir da guerra

Excerto da notícia: Primeira brasileira de uma família de refugiados, Hannah sonha com uma vaga no ensino superior do país onde nasceu [...] (O Globo, 06 nov. 2016) $)^{12}$.

12 Disponível em: https://oglobo.globo.com/sociedade/educacao/enem-e-vestibular/enem-2016-filha-derefugiados-tenta-vaga-no-ensino-superior-20420476. Acesso em: 31 jul. 2019. 
Tentar uma vaga no ensino superior é uma expressão reformulada, no corpo da notícia, como o sonho de Hannah, sonho este atrelado à universidade como possibilidade de reenraizamento, já que Hannah não é designada refugiada, mas brasileira. Podemos observar, na formulação do título, que o ingresso no ensino superior é construído como uma tentativa, sem garantias, ou seja, tentar uma vaga é apostar na promessa de ter para si um lugar, o que pode ser lido também como possibilidade de ser sujeito, ainda que desancorado das referências do país de origem de seus familiares. Sendo apenas "filha de refugiados", Hannah deve construir sua própria história no país que é o seu.

Na construção discursiva da notícia, o que emerge da memória coletiva é o "sonho" de alcançar direitos básicos de cidadão de uma nação, dentre os quais o de ter acesso a uma formação superior. Assim, embora filha de refugiados, o sonho da brasileira Hannah não dialoga apenas com as expectativas das pessoas em situação de refúgio, mas de outros(a)s jovens brasileiro(a)s, para quem tentar uma vaga no ensino superior é uma aspiração, sendo muito(a)s de nosso(a)s estudantes também o(a)s "primeiro(a)s da família" a conseguir tal lugar. Esse modo de enunciar presentifica uma memória discursiva pela qual muitos jovens no Brasil - refugiados ou não - nem sempre podem ingressar em uma universidade, apontando para a dimensão social desse distanciamento, uma vez que, historicamente, a universidade é um lugar para poucos e um sonho para muitos.

Nesse sentido, falar do acesso à universidade envolve, para além das condições sociais, políticas e econômicas, a dimensão subjetiva do investimento de si - ou do "mérito pessoal" - na (re)construção de um novo lugar, de uma nova vida (como sugere também a notícia "Refugiados da Síria e África reconstroem suas vidas em Niterói”, de 2015). Muito embora o discurso jornalístico se embase na reprodução de "discursos hegemônicos sobre o valor 'trabalho' para conferir legitimidade aos imigrantes" (JARDIM, 2016, p. 251), a universidade é apresentada como esse outro lugar possível, mas também distante, não fisicamente, como a terra natal, mas social e historicamente.

Nas notícias difundidas a partir de 2017, entretanto, a ênfase do texto jornalístico deixa de incidir sobre a "saga" individual em busca de validação ou de formação e passa a se dar sobre a "abertura" institucional.

SD3) Manchete: Cresce $n^{\circ}$ de universidades brasileiras que acolhem refugiados

Excerto da notícia:

Sonho

A jovem já trabalha em um escritório de arquitetura e faz planos para o futuro. Ela quer tornar realidade seu trabalho final de curso - o projeto arquitetônico de um centro de acolhimento para refugiados (O Estado de São Paulo, 11 set. 2017) ${ }^{13}$.

Essa mudança de enfoque é perceptível na estrutura linguística do título, na SD3, em que "universidades" é o agente do processo. Logo, a universidade é construída como lugar de acolhida, em um movimento que silencia o custo, a demora, o drama, as tentativas dos refugiados, que agora contam com a abertura das instituições. Embora o

13 Disponível em: https://educacao.estadao.com.br/noticias/geral,cresce-n-de-universidades-brasileirasque-acolhem-refugiados,70001984155. Acesso em: 31 jul. 2019. Esse modo de apresentação da notícia já é visível nas manchetes de 2016 e se acentua naquelas de 2019, conforme apresentado na Tabela 1. 
texto da notícia dedique-se a contar a história de alguns deles, o que está em pauta é o modo como a universidade não mais se caracteriza como um sonho (difícil, distante), mas como a possibilidade de concretização de projetos reais (de "fazer planos", de "tornar realidade seu trabalho").

A lógica da acolhida rege o tom da notícia e parece desencadear um processo mútuo, pois, tendo encontrado acolhida/refúgio na universidade, a estudante planeja acolher outros refugiados. Embora continuem ressoando vozes que significam a universidade como porta de entrada para o mercado de trabalho, sendo o refugiado uma mão de obra qualificada, o aspecto social desse trabalho, como inserção local, passa a ganhar mais destaque nas notícias.

Reverberando os discursos institucionais e humanitários, constrói-se, assim, a universidade como meio de integração e promessa de mobilidade social em um sistema de acesso historicamente desigual. Contudo, o fato de nem sempre serem explicitadas as razões dessa abertura institucional pode produzir nos leitores, afeitos apenas à leitura superficial no espaço digital, um efeito tanto de "favoritismo" das pessoas refugiadas quanto de um processo de acesso "facilitado", visto negativamente. A SD4, a seguir, publicada em 2018, incide sobre esses aspectos até aqui levantados.

\section{SD4) Manchete: Só 2 de cada 10 vagas para refugiados em universidades no Brasil são preenchidas}

Linha de apoio: Apesar de ociosidade alta, número de matriculados e de instituições que os recebe cresce

Excerto da notícia: Para Federico Martinéz, representante-adjunto do Acnur no Brasil, os esforços do grupo são um exemplo a ser seguido no resto do país, $e$ constituem um "passo fundamental para que os refugiados possam reiniciar suas vidas no Brasil, promovendo efetivamente sua integração local", diz ele, que afirma também que as instituições de ensino brasileiro estão na vanguarda (Folha de São Paulo, 14 set. 2018) ${ }^{14}$.

Diferentemente das manchetes abordadas nas SDs anteriores, a SD4 se estrutura de modo a produzir uma falsa conclusão negativa sobre a abertura da universidade, ao apresentar a proporção de 2 ingressantes para cada 10 vagas. Esse efeito da manchete é contradito pela linha de apoio e pela notícia em si, que destacam positivamente o aumento, também numérico, nas inscrições e nas instituições. A apresentação das migrações como uma realidade numérica, portanto, demonstrável (BRÉANT, 2012), é recorrente nos âmbitos midiático e institucional. Desse modo, abordar o acesso à universidade em termos numéricos também é uma regularidade nesses discursos. Para Bréant (2012, p. 156), "recorrer aos números como meio de legitimação de um argumento é considerar, ao mesmo tempo, que eles dispõem de uma veracidade própria ou de uma verdade intrínseca e que dispensam uma reflexão sobre suas modalidades de produção"15.

14 Disponível em: https://www1.folha.uol.com.br/mundo/2018/09/refugiados-ocupam-23-de-vagasreservadas-a-eles-em-universidades-no-brasil.shtml. Acesso em: 31 jul. 2019.

${ }^{15}$ No original: "Recourir aux nombres en tant que moyen de légitimation d'un argumentaire, c'est à la fois considérer qu'ils disposent d'une véracité propre, ou d'une vérité intrinsèque, et qu'ils dispensent d'une réflexion sur leurs modalités de production". 
Se os números se tornam uma forma de prova na argumentação institucional/jornalística, legitimando um argumento, e se as instituições de ensino são, em grande parte, legitimadoras das posições sujeito que nela se constituem, a compreensão numérica das migrações e, consequentemente, de seu acesso ao ensino superior pode contribuir para que pessoas refugiadas sejam vistas tanto como legítimas quanto como ilegítimas nesse espaço. Dito de outro modo, se existem milhões de pessoas em deslocamento no mundo e apenas $1 \%$ tem acesso ao ensino superior (no caso brasileiro, 3\%), facilitar esse ingresso, a partir de uma perspectiva humanitária, é uma forma legítima de promover a mobilidade econômica, social e cultural. Contudo, se há tantas vagas para poucos ou se muitas vagas destinadas a essa população permanecem ociosas, para a opinião pública - em grande medida inscrita em práticas discursivas que defendem a meritocracia individual -, o gesto de destinar vagas a pessoas refugiadas em processos seletivos específicos pode ser visto como ilegítimo.

A construção da notícia, na SD4, joga com essa memória e com essa heterogeneidade "irredutíveis" no discurso, ou seja, com esse remoer de dizeres, principalmente no campo digital, em que o leitor pode facilmente reagir e interagir, reforçando-os ou questionando-os. Em sua base, assim como na SD3, subjaz uma concepção social-liberal, segundo a qual a acolhida institucional, por si só, permitiria aos refugiados se tornarem agentes, empoderados e empreendedores na reconstrução de suas vidas (CHEVALIER, 2019). Assim, a heterogeneidade, marcada pela voz do outro (representante-adjunto do Acnur no Brasil) nessa notícia, não enuncia a relação entre migração e ingresso/reconhecimento no ensino superior a partir da lógica das relações de trabalho, como se pode ver em outras SDs, uma vez que insiste sobre a legitimidade da "integração", em sintonia (como se pode esperar), com o que apregoa o discurso institucional que representa.

No que concerne a essa "integração local", a universidade seria essa instituição na vanguarda, que contribui para que seja efetiva e para que os refugiados "reiniciem" suas vidas. Nesse sentido, embora marcadamente pró-ingresso e pró-migrações no ensino superior, o dizer e, de forma mais ampla, a notícia, não constroem as universidades como espaços multiculturais ou de continuação de uma vida e de uma formação já em curso, mas sobretudo, como lugares de recomeço, inscrevendo-se, assim, em práticas discursivas, logo sócio-históricas, que podem tender ao assimilacionismo do outro/estrangeiro, pois, como aponta Barats (2018, p. 126), o termo integração emerge no dispositivo jurídico como alternativa a "assimilação", na qual se entende ressoar um passado colonial. Portanto, inclusão e integração não são sinônimos, principalmente no domínio sempre conflitante dos discursos institucionais. Se incluir pode permitir conceber e receber o outro em suas diferenças, integrar pode demandar a adaptação desse outro, sua conformação a dado modo de vida e, por consequência, um reinício, tomado como necessário para a inserção, a depender do contexto social e político em questão.

A notícia em foco produz, assim, como realidade, o fato de a universidade se construir como possibilidade de recomeço (ou de reconstrução, como afirmam, em certa medida, as SD2 e SD3) das vidas dos refugiados. Esse modo de construir essa instituição, por meio de enunciados que, embora dissonantes, enfatizam seu protagonismo, inscrevem-se (e inscrevem-na) em práticas discursivas que constroem, no/pelo discurso 
jornalístico, outras formas de compreender a relação entre refúgio e educação superior. Assim, é pertinente apontar que, embora fortemente atravessado pelo discurso jurídicoadministrativo - no que concerne à situação das pessoas refugiadas - e pelo discurso hegemônico capitalista - no que tange ao papel da universidade como via de acesso ao mercado de trabalho e, consequentemente, de ascensão/inserção econômica -, o discurso midiático também pode possibilitar a instauração de outros sentidos, mais "integrativos", embora não alheios à lógica liberal contemporânea. Esses sentidos, mesmo diferentes, ancoram-se em uma realidade semelhante, na qual a "eles" ou não se atribui capital simbólico, como se a posição "refugiado" fosse a única possível de ser assumida no discurso sobre, ou se delega toda a parcela de ação para a reconstrução de sua história.

A última SD analisada incide sobre o pré-construído, segundo o qual o direito ao ensino superior, previsto na convenção de Genebra, implica certo papel indulgente das instituições, que acolheriam de forma aparentemente protecionista, sem que a vinda do estrangeiro lhes trouxesse qualquer benefício.

\section{SD5) Manchete: Justiça determina suspensão de processo seletivo para refugiados e imigrantes na UFRR \\ Linha de apoio: UFRR suspendeu provas e aberturas de novas inscrições. Programa estava em vigor desde julho de 2018; vagas ofertadas eram remanescentes de outros editais na universidade \\ Excerto da notícia: Na decisão, a juíza entendeu que a UFRR, ao criar um programa de acesso à educação superior para solicitantes de refúgio, refugiados e imigrantes em situação de vulnerabilidade, "extrapolou os limites constitucionais e legais". Ela afirmou ainda que os critérios da resolução que criou a seleção são "nitidamente, desproporcionais e em flagrante ofensa ao princípio constitucional da igualdade, gerando uma discriminação reversa injustificável." (G1, 30 nov. 2019) ${ }^{16}$.}

A SD5 é a única que destoa das demais notícias publicadas acerca do ingresso no ensino superior, na medida em que versa, não sobre a abertura, mas sobre a impossibilidade desse acesso. Na materialidade linguística, a manchete desloca o papel de agente da instituição de ensino para a justiça, de modo que o protagonismo institucional, presente em outras manchetes, principalmente no ano de 2019, cede ao que ordena o domínio jurídico. Tal âmbito é personificado na voz e na figura da juíza que decide suspender o programa de ingresso de uma universidade específica; programa este, como destaca a linha de apoio, que estava em vigor há pouco tempo e que destinava vagas remanescentes a imigrantes. Cabe à universidade em questão, então, suspender o processo seletivo e as novas inscrições ao programa de acesso.

A passagem, no enredo das notícias, da ênfase dada à história dos refugiados para as instituições e, então, para a justiça permite apontar certo modo de leitura, feita pelo discurso jornalístico, dos saberes-poderes em funcionamento nos dizeres e na conjuntura histórica em questão. Na medida em que não só informa, mas também produz conhecimento, orquestrado pelo que se entende como devendo ou não ser notícia, o

16 Disponível em: https://g1.globo.com/rr/roraima/noticia/2019/11/30/justica-determina-suspensao-deseletivo-para-refugiados-e-imigrantes-na-ufrr.ghtml. Acesso em: 20 abr. 2020. 
discurso jornalístico remonta às diferentes práticas discursivas em que se inscrevem os sujeitos quando enunciam e, assim, contribuem na construção e na permanência de dada realidade.

No caso da SD5, o dizer da juíza, que também emana de um conjunto difuso de vozes, funciona de forma profundamente evidente e opaca (PÊCHEUX, 1990), como observado acerca da SD1. Naquela, soa evidente que o não acesso ao ensino superior implica a precarização das condições de trabalho, em uma preocupação com “eles", os refugiados, a quem se deve integrar como força produtiva para que possam ser sujeitos sociais. Nesta, soa evidente que, sendo estrangeiros, "solicitantes de refúgio, refugiados e imigrantes", "eles" não devem se beneficiar de direitos legais e constitucionais dos brasileiros.

Embora, na conjuntura histórica e política atual, mais de quarenta mil pessoas tenham sido reconhecidas como refugiadas no Brasil entre 2019 e $2020^{17}$, a memória discursiva acerca do que podem ou não podem os refugiados fundamenta a decisão de que um processo facilitado seria desigual, desproporcional e caracterizaria "uma discriminação reversa". A opacidade do dizer, dada a polêmica e a indefinição em torno dessa suposta discriminação, contribui, politicamente, para a construção da universidade não mais como lugar de igualdade, de acessibilidade ou de integração, mas de uma também suposta desigualdade entre habitantes de um mesmo país.

As notícias analisadas nessas cinco SDs, embora brevemente, possibilitam reforçar, conforme apontado, que há uma dimensão política em todo dizer, na medida em que esta se relaciona à linguagem, enquanto sistema simbólico de representações e valores, inseparável das condições sócio-históricas em que esse dizer emerge. No discurso jornalístico em meio digital, as disputas de sentidos se dão pela opacidade do discurso e em relação às indefinições do presente, no qual se estabilizam, mas também se ressignificam sentidos.

\section{CONSIDERAÇÕES FINAIS}

A análise aqui apresentada permite-nos compreender que a circulação do discurso jornalístico on-line sobre o ingresso de refugiados no ensino superior, por um lado, inserese (e os insere) em uma dinâmica econômica, o que não seria diferente, dadas as condições sócio-históricas contemporâneas, em que o discurso midiático (re)produz o discurso hegemônico, pautado nos moldes capitalistas de produção, reprodução e divisão das relações de trabalho. Logo, encontrar na falta de formação universitária ou de reconhecimento do diploma acadêmico uma razão para as pessoas refugiadas ocuparem os lugares mais baixos na esfera trabalhista, ao mesmo tempo em que soa evidente, superficializa e escamoteia não só a complexidade do processo migratório (prenhe de preconceitos das mais diversas ordens), mas também a parcela de contribuição que o olhar do estrangeiro oferece na sociedade, nas relações de trabalho e na universidade.

\footnotetext{
${ }^{17}$ Notícia a esse respeito disponível em: https://g1.globo.com/politica/noticia/2020/01/31/brasil-reconheceem-bloco-17-mil-venezuelanos-como-refugiados.ghtml. Acesso em: 20 abr. 2020.
} 
Quanto a esta última, temos observado contemporaneamente e em escala mundial que os processos de internacionalização estão ligados, prioritariamente, a políticas de "excelência acadêmica". No Brasil, diversos programas foram criados em favor da expansão, da popularização, bem como da internacionalização de nossas universidades. Contudo, o ingresso de estudantes estrangeiros(as)-refugiados(as) nessas instituições - ao menos no discurso jornalístico textualizado nas notícias observadas - não costuma ser visto como parte das políticas que visam à internacionalização acadêmica e à acolhida de estudantes/pesquisadores internacionais, mas das chamadas políticas de integração ou reinserção social.

Nesse sentido, deslocar o modo de compreender o movimento de internacionalização das universidades e de acolhida ao estrangeiro pode se caracterizar como uma possível reconfiguração dos pré-construídos que compartilhamos sobre o que é e como funciona a universidade, sobre quem tem e quem não tem acesso legítimo a ela; memória que se estende socialmente e reverbera, principalmente, pelo discurso jornalístico. Em outros termos, o estudo aqui desenvolvido propõe que se pense essa internacionalização, no sentido evocado por Ajari (2019), de modo a perguntar qual interesse compartilhamos com os outros oprimidos, "quais são as características e campos de ação possíveis que temos em comum" 18 . Nesse quadro, o discurso midiático pode contribuir para uma "luta pela visibilidade", enquanto "dimensão específica do agir que, partindo de um vivido da invisibilidade ou da depreciação simbólica [dos países do Sul ou "em desenvolvimento"], desenvolve procedimentos práticos, técnicos e comunicacionais para se manifestar em uma cena pública"19 (VOIROL, 2005, p. 107-108, [inserção nossa]).

Desse modo, analisar o discurso e o papel das mídias na história do presente, na produção de conhecimento e na divulgação desses sentidos (outros) consiste em um desafio que se impõe aos estudos do discurso atuais. A análise possibilita, assim, que nos interroguemos sobre a opacidade, a porosidade e, mesmo, a fragilidade de certos préconstruídos que atravessam as práticas discursivas midiáticas, de modo a compreender que a falta de atenção da imprensa ao acesso de pessoas refugiadas à educação pode reforçar o fato de que essa pauta foge à "retórica da informação espetáculo" (KOREN, 2013). Essa tomada de posição dificulta que as mídias atuem socialmente como produtoras e transmissoras de conhecimento ou como questionadoras de estruturas históricas desiguais.

$\mathrm{Na}$ ausência de políticas nacionais que acompanhem as dinâmicas migratórias no país e diante da ameaça às poucas iniciativas de acolhida ao estrangeiro, como são os programas de ingresso nas universidades brasileiras, refletir sobre a potencialidade e a dimensão política do discurso midiático/jornalístico permite compreender e questionar a realidade em construção no tempo presente. Mas, acima de tudo, possibilita vislumbrar o que projetamos, desse presente, no futuro.

\footnotetext{
${ }^{18}$ No original : "Quel intérêt je partage avec les autres opprimés, quelles sont les caractéristiques et quels sont les terrains d'action possible que nous avons en commun".

19 No original: "cette dimension spécifique de l'agir qui, partant d'un vécu de l'invisibilité ou de la dépréciation symbolique, déploie des procédés pratiques, techniques et communicationnels pour se manifester sur une scène publique".
} 
AGIER, M. L'étranger qui vient. Paris: Seuil, 2018.

AJARI, N. Penser politiquement race, classe et genre au-delà de l'intersectionnalité. In : ECOLE DECOLONIALE 2019-2020, 2019, Paris.

AKIN, S. Sans-papiers : une dénomination dans cinq quotidiens nationaux de mars à août 1996. Mots : les langages du politique, n. 60, p. 59-75, 1999. Disponível em: https://www.persee.fr/doc/mots_02436450_1999_num_60_1_2164. Acesso em: 20 abr. 2020.

AKOKA, K. Distinguer les réfugiés des migrants au XXe siècle : Enjeux et usages des politiques de classification. In: AGIER, M. ; MADEIRA, A.-V. (Org.). Définir les réfugiés. Paris: PUF, 2017, p. 47-68.

AKOKA, K. Qu'est-ce qu'un réfugié ? Des usages politiques des définitions juridiques. In:

CALABRESE L. ; VENIARD M. (Org.). Penser les mots, dire la migration. Paris: Academia, 2018, p. 183-188.

ANGERMULLER, J. Academic careers and the valuation of academics. A discursive perspective on status categories and academic salaries in France as compared to the U.S., Germany and Great Britain. High Educ, n. 73, p. 963-980, 2017. Disponível em: https://link.springer.com/article/10.1007/s10734-0170117-1. Acesso em: 20 abr. 2020.

AUTHIER-REVUZ, J. Heterogeneidades enunciativas. Cadernos de Estudos Linguísticos, Campinas, v. 19, p. 25-42, jul.-dez. 1990. Disponível em:

https://periodicos.sbu.unicamp.br/ojs/index.php/cel/article/view/8636824/4545. Acesso em: 9 jan. 2019.

BARATS, C. De l'intégration comme processus à l'exigence d'intégration. In: CALABRESE L. ;

VENIARD M. (Org.). Penser les mots, dire la migration. Paris: Academia, 2018, p. 125-132.

BRÉANT, H. Démontrer le rôle positif des migrations internationales par les chiffres. Une analyse de la rhétorique institutionnelle du système des Nations Unies. Mots. Les langages du politique, n. 100, p. 153171, 2012. Disponível em: https://journals.openedition.org/mots/20987. Acesso em: 14 abr. 2020.

BUENO, A. M. Estilos de vida de imigrantes e refugiados nos meios de comunicação. Gragoatá, Niterói, v. 22, n. 42, p. 289-307, jan.-abr. 2017. Disponível em: http://dx.doi.org/10.22409/gragoata.2017n42a865. Acesso em: 10 set. 2019.

CALABRESE, L. Reformulation et non-reformulation du mot islamophobie. Une analyse des dynamiques de la nomination dans les commentaires des lecteurs. Langue Française, v. 4, n. 188, p. 91104, 2015. Disponível em: https://www.cairn.info/revue-langue-francaise-2015-4-page-91.htm\#. Acesso em: 14 abr. 2020.

CANUT, C. Migrants et réfugiés : quand dire, c'est faire la politique migratoire. Vacarme, n. p., 2016. Disponível em: https://vacarme.org/article2901.html. Acesso em: 2 fev. 2019.

CANUT, C.; GUELLOUZ, M. Introduction. Langage et migration : état des lieux. Langage et Société, n. 165, p. 9-30, 2018/3. Disponível em: https://www.cairn.info/revue-langage-et-societe-2018-3-page-9.htm. Acesso em: 2 fev. 2019.

CHEVALIER, T. Résister à bas bruit aux catégorisations institutionnelles dans des dispositifs de participation à Berlin. Participations, n. 25, p. 109-138, 2019/3. Disponível em :

https://www.cairn.info/revue-participations-2019-3-page-109.htm. Acesso em: 14 abr. 2020.

COURTINE, J.-J. O tecido da memória: algumas perspectivas de trabalho histórico nas ciências da linguagem. Polifonia, Cuiabá, v. 12, n. 2, p. 1-13, 2006. Disponível em:

http://periodicoscientificos.ufmt.br/ojs/index.php/polifonia/article/view/1067/840. Acesso em: 14 abr. 2020.

COURTINE, J.-J.; MARANDIN, J.-M. Que objeto para a análise de discurso? In: CONEIN, B. et. al. (Org.). Materialidades discursivas. Campinas: EDUNICAMP, 2016, p. 33-54.

FERRAGUT, G. MPL E MBL: a avenida paulista e o movimento antes de P e B - uma reflexão sobre a formação algorítmica. Línguas e Instrumentos Linguísticos, n. 44, p. 112-134, jul.-dez. 2019. Disponível em: https://periodicos.sbu.unicamp.br/ojs/index.php/lil/article/view/8657789/21809. Acesso em: 14 abr. 2020.

FOUCAULT, M. A arqueologia do saber. Rio de Janeiro: Forense Universitária, 2009.

FOUCAULT, M. A ordem do discurso. São Paulo: Edições Loyola, 2001. 
FOUCAULT, M. Le monde est un grand asile. In: FOUCAULT, M. Dits et Ecrits. Tomo II, texto n.126, 1994, p. 434.

GREGOLIN, M. R. Análise do discurso e mídia: a (re)produção de identidades. Comunicação, Mídia e Consumo, São Paulo, v. 4, p. 11-25, nov. 2007. Disponível em: http://revistacmc.espm.br/index.php/revistacmc/article/view/105/106. Acesso em: 16 nov. 2018.

GUILHAUMOU, J.; MALDIDIER, D.; ROBIN, R. Discurso e arquivo: experimentações em Análise do Discurso. Campinas: EDUNICAMP, 2016.

JARDIM, D. Imigrantes ou refugiados? As tecnologias de governamentalidade e o êxodo palestino rumo ao Brasil no século XX. Horizontes Antropológicos, Porto Alegre, ano 22, n. 46, p. 243-271, jul./dez. 2016. Disponível em: https://doi.org/10.1590/S0104-71832016000200009. Acesso em: 20 abr. 2020. KOREN, R. Ni normatif ni militant : le cas de l'engagement éthique du chercheur. Argumentation et Analyse du Discours, n. 11, p. 01-19, 2013. Disponível em: http://journals.openedition.org/aad/1572. Acesso em: 07 out. 2019.

LE GOFF, J. História e memória. Campinas: EDUNICAMP, 1996.

LENETTE, C.; BAKER, S.; HIRSCH, A. Systemic Policy Barriers to Meaningful Participation of Students from Refugee and Asylum Seeking Backgrounds in Australian Higher Education. In: MCBRIEN, J. (Org.). Educational policies and practices of English-speaking refugees resettlement countries. Leiden/Boston: Brill Sense, 2019. p. 88-109.

NOSSIK, S. Des Dublins aux dubliné-e-s: dérivations de la violence administrative. In: CALABRESE L.; VENIARD M. (Org.). Penser les mots, dire la migration. Paris: Academia, 2018, p. 81-90.

SÉRIOT, P. Langue russe et discours politique soviétique : analyse des nominalisations. Langages, Paris, n. 81, p. 11-41, 1986.

PÊCHEUX, M. Abertura do colóquio. In: CONEIN, B. et. al. (Org.). Materialidades discursivas. Campinas: EDUNICAMP, 2016. p. 25-29.

PÊCHEUX, M. Papel da memória. In: ACHARD, P. et al. (Org.) Papel da memória. Campinas: Pontes, 1999. p. 49-57.

PÊCHEUX, M. O discurso: estrutura ou acontecimento. Campinas: Pontes, 1990.

RASIA, G. Sobre a noção de práticas linguageiras: lugares de emergência, filiações e fronteiras.

Fragmentum, Santa Maria, n. 52, p. 165-187, jul./dez. 2018. Disponível em:

https://periodicos.ufsm.br/fragmentum/article/view/33673/pdf. Acesso em: 8 mar. 2019.

ROBLAIN, A., 2018, Allochtone : une dénomination euphémisante devenue polémique. In:

CALABRESE L. ; VENIARD M. (Org.). Penser les mots, dire la migration. Paris: Academia, 2018, p. 43-48.

ROULLEAU-BERGER, L. Migrer au féminin. Paris: PUF, 2010.

SCHWAAB, R. T. Para ler de perto o jornalismo: uma abordagem por meio de dispositivos da análise do discurso. Em Questão, v. 13, n. 1, p. 11-23, jan.-jun. 2007. Disponível em:

https://www.redalyc.org/articulo.oa?id=465645956002. Acesso em: 20 maio 2018.

STEVENSON, J.; BAKER, S. Refugees in higher education: debate, discourse and practice. Bingley: Emerald Publishing Limited, 2018.

VOIROL, O. Les luttes pour la visibilité. Esquisse d'une problématique. Réseaux, n. 129-130, p. 89-121, 2005/1. Disponível em: https://www.cairn.info/revue-reseaux1-2005-1-page-89.htm. Acesso em: 20 mai. 2018.

ZANELLA, A. Considerações sobre os portais de notícia on-line: falamos, ainda, de discurso jornalístico? In: SEMINÁRIO DOS ALUNOS DOS PROGRAMAS DE PÓS-GRADUAÇÃO DO INSTITUTO DE LETRAS DA UFF - Estudos de Linguagem. 6., Niterói, 2015. Anais... n. 1, p. 27-34, 2015. Disponível em: http://www.anaisdosappil.uff.br/index.php/VISAPPIL-Ling/article/view/238/133. Acesso em: 15 fev. 2019.

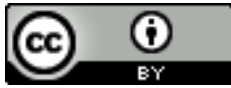

Este texto está licenciado com uma Licença Creative Commons Atribuição 4.0 Internacional. 